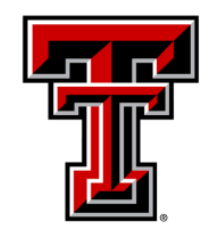

TEXAS TECH UNIVERSITY

Libraries"

\title{
PERPENDICULAR EDGE ORIENTED GRAPHENE FOAM SUPPORTING ORTHOGONAL TIO2(B) NANOSHEETS AS FREESTANDING ELECTRODE FOR LITHIUM ION BATTERY
}

\section{The Texas Tech community has made this publication openly available. Please share how this access benefits you. Your story matters to us.}

\begin{tabular}{|l|l|}
\hline Citation & $\begin{array}{l}\text { Ren, G., Hoque, M. N. F., Liu, J., Warzywoda, J., \& Fan, Z. (2016). } \\
\text { Perpendicular edge oriented graphene foam supporting orthogonal } \\
\text { TiO 2 (B) nanosheets as freestanding electrode for lithium ion } \\
\text { battery. Nano Energy, 21, 162-171. } \\
\text { http://dx.doi.org/10.1016/i.nanoen.2016.01.010 }\end{array}$ \\
\hline Citable Link & $\underline{\text { http://hdl.handle.net/2346/68135 }}$ \\
\hline Terms of Use & $\underline{\text { CC BY-NC-ND 4.0 }}$ \\
\hline
\end{tabular}




\title{
Perpendicular Edge Oriented Graphene Foam Supporting Orthogonal $\mathrm{TiO}_{2}(\mathrm{~B})$ Nanosheets as Freestanding Electrode for Lithium Ion Battery
}

Guofeng Ren ${ }^{1}$, Md Nadim Ferdous Hoque ${ }^{1}$, Jianwei Liu, ${ }^{2}$ Juliusz Warzywoda ${ }^{3}$, and Zhaoyang $\operatorname{Fan}^{1 *}$

${ }^{1}$ Department of Electrical and Computer Engineering and Nano Tech Center, Texas Tech University, Lubbock, Texas, 79409, USA.

${ }^{2}$ Department of Physics and Astronomy, University of Kansas, Lawrence, KS 66045, USA.

${ }^{3}$ Materials Characterization Center, Whitacre College of Engineering, Texas Tech University, Lubbock, Texas 79409, USA.

* Corresponding author: zhaoyang.fan@ttu.edu

\begin{abstract}
We report three-dimensional (3D) freestanding electrodes based on edge-oriented multilayer graphene (EOG) foam loaded with oriented $\mathrm{TiO}_{2}(\mathrm{~B})$ nanosheets for lithium ion battery that exhibits large capacity and extremely long cycling stability. In contrast to the commonly reported graphene/graphite foams (GFs) that consist of lateral graphene/graphite sheets, EOG foam, with perpendicular graphene network to fully expose the chemically active graphene edges, was developed as a better scaffold to support active materials. Orthogonally oriented $\mathrm{TiO}_{2}(\mathrm{~B})$ nanosheets were densely grown on the EOG foam but had straight channels for facile electrolyte access, thus producing a rationally-designed nanostructured architecture. Such a $\mathrm{TiO}_{2}(\mathrm{~B}) / \mathrm{EOG}$ freestanding electrode demonstrated large capacities and high-rate performance. It particularly exhibited unprecedented cycling stability with capacity retention of $82 \%$ after 12,000 charge-
\end{abstract}


discharge (C-D) cycles. It is expected this new electrode architecture as well as the EOG foam will find broad applications in further development of high performance lithium ion batteries and other electrochemical energy technologies.

\section{Introduction}

Considerable efforts are being devoted to improving the performance of lithium-ion batteries (LIBs). In addition to the high energy density characteristics, high power capability, fast charging rate, good safety, and long charge-discharge cycling stability or life-time are highly desirable features of LIBs. Nanostructured electrodes are under intensive investigation for such high rate and high power LIBs.[1-4] Further improvement of the cycling stability of LIBs with a longer lifetime is also important.

To achieve the high rate or high power capability, mitigating the high-resistance problem of transition metal oxides is critical. 3D freestanding nanostructured electrodes, with active electrode materials anchored on a conductive framework that is also directly used as a current collector, are being studied, $[2,3,5]$ with the aim to address the interrelated issues of energy density, power density, charge-discharge rate, and cycling stability of electrochemical energy storage devices, especially LIBs. 3D freestanding multilayer-graphene or thin-graphite foam (GF),[6] produced by chemical vapor deposition (CVD) of continuous multilayer-graphene or thin-graphite film along the strut surface of nickel foam and then etching away nickel struts, is a promising candidate for the conductive framework, thanks to its high conductivity, small mass, and chemical and mechanical stability. Such CVD GF is much better than foams formed by individual reduced graphene oxide nanosheets that have poor conductivity and mechanical strength due to the weak contact between sheets.[7] Therefore, the CVD GFs are being explored as both a current collector and a framework for supporting active nanomaterials to construct freestanding electrodes for high 
rate capability.[8-11] However, we emphasize that since graphene or thin-graphite sheets were grown conformably (or laterally) along the nickel strut surface, such a GF has a limited surface area and roughness. Although macroscopically, it has a 3D foam structure, at a smaller scale of hundreds of micrometer, it is still a flat 2D structure. The graphene edges, the "hot spots" for chemical bonding to the active electrode material, are generally not accessible. Therefore, a different kind of GF that retains the merits of this previously demonstrated GF, but has a large and easily accessible surface area and fully exposed dense graphene edges, is highly desirable as the electrode framework for energy storage as well as for catalysis, sensing and numerous other applications.

Plasma enhanced CVD (PECVD) can produce dense, vertically oriented multilayer graphene-based network on different substrates, which has been explored for energy conversion and storage applications[12-17] due to its well-open porous structure, large surface area, and high conductivity, as was recently reviewed.[18] Considering all its merits, herein, we report a new format of continuous edge-oriented GF, EOG foam. Here, we call the previously reported GF as laterally oriented graphene/graphite (LOG) foam for differentiation. EOG network was first grown around the struts of nickel foam by PECVD. After etching off nickel struts, freestanding EOG foam is formed. Using it as a low mass, large surface area, and highly conductive framework, many resistive materials can be deposited to construct nanostructured freestanding electrodes. In this work, we are particularly interested in $\mathrm{TiO}_{2}(\mathrm{~B})$.

Bronze-phase $\mathrm{TiO}_{2}(\mathrm{~B})$, one of the several polymorphs of titania, has been considered as a promising anode material for LIBs.[19-21] Its reasonable potential, i.e., $\sim 1.6 \mathrm{~V} \mathrm{vs.} \mathrm{Li}^{\prime} / \mathrm{Li}^{+}$, prevents lithium plating-related catastrophic safety issue from occurring. Its minor lattice expansion/contraction during $\mathrm{Li}^{+}$insertion/extraction is intrinsically beneficial for long cycling 
stability and lifetime. Perhaps the most prominent feature of $\mathrm{TiO}_{2}(\mathrm{~B})$ is its unique non-diffusionlimited ion insertion/extraction process, or the pseudocapacitance based charge storage mechanism,[22] that provides a basis for potentially high-rate performance of $\mathrm{LIBs}^{\mathrm{B}} \mathrm{Bulk} \mathrm{TiO}_{2}(\mathrm{~B})$ suffers from limited electronic conductivity and low ion diffusion coefficient. Thus, considerable interest has been devoted to studies of $\mathrm{TiO}_{2}(\mathrm{~B})$ nanomaterials for reduction of electron and ion transport distances. Nanoparticles,[23] mesoporous microspheres,[24] nanowires,[25-28] nanorods,[29] nanobelts,[30] nanotubes,[31-33] nanosheets,[34-38] nanoribbons,[39, 40] and many other structures[20] all have been investigated to reveal the pseudocapacitive lithiation/delithiation process and the nanostructure impact on its capacity, capacity loss, and rate capability. In particular, fast rate and extraordinary cycling stability performances have been reported using mesoporous $\mathrm{TiO}_{2}(\mathrm{~B})$ microspeheres,[24] and nanoparticulate $\mathrm{TiO}_{2}(\mathrm{~B}),[41]$ and recently using elongated $\mathrm{TiO}_{2}(\mathrm{~B})$ nanotubes.[32] A quasi-2D sheet geometry might be a better option that can offer the high capacity and high rate performance, while at the same time, the flexible sheets with negligible surface strain may also mitigate the issue of electrolyte degradation and the subsequent capacity loss.[20]

Herein we report formation of the orthogonally oriented $\mathrm{TiO}_{2}(\mathrm{~B})$ nanosheets which are densely packed around the EOG foam to construct a high-performance freestanding electrode with high rate capability. This electrode also demonstrated long cycling stability with $82 \%$ retention after over 12,000 cycles at $8 \mathrm{C}$ rate. 


\section{Results and Discussion}

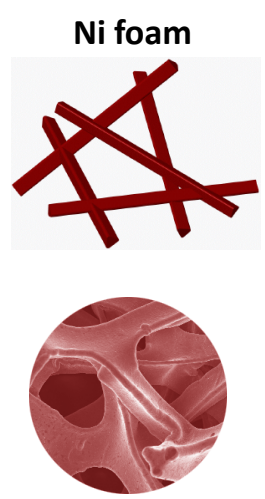

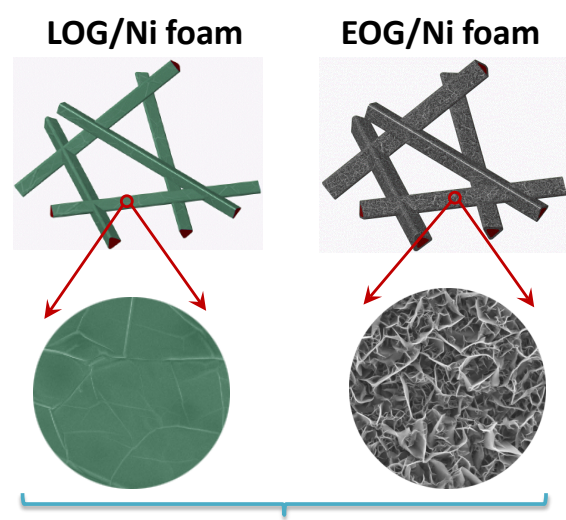

PECVD deposition

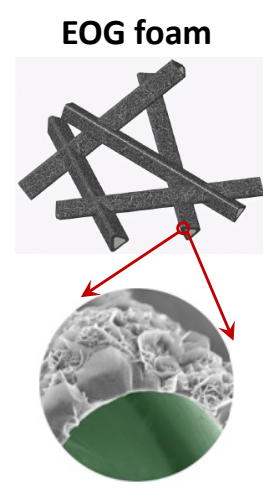

Wet etch
$\mathrm{TiO}_{2}$ (B)/EOG

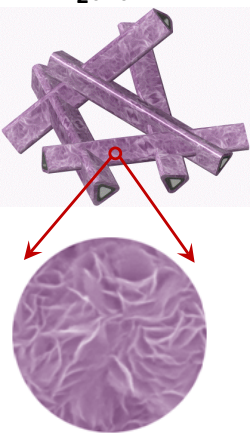

Solvothermal growth

Figure 1. Schematics illustrate the process used to produce the freestanding $\mathrm{TiO}_{2}(\mathrm{~B}) / \mathrm{EOG}$ electrode. Starting from a Ni foam as the support, $L O G$ and then EOG are deposited in a PECVD process. When the underlying Ni foam is etched away, freestanding EOG foam is produced. Subsequently, orthogonally oriented $\mathrm{TiO}_{2}(\mathrm{~B})$ nanosheets are synthesized on EOG in a solvothermal process.

Figure 1 schematically illustrates the overall process to produce the freestanding electrode. Using a bare nickel foam in a PECVD deposition process, laterally oriented multilayer-graphene or thin-graphite film is first formed along the strut surface of the nickel foam, and this is followed by vertical flakes nucleating and growing into interconnected EOG network. Subsequently, the underlying nickel foam is chemically etched off to produce freestanding EOG foam with greatly reduced mass. Finally, in a solvothermal synthesis process, dense $\mathrm{TiO}_{2}(\mathrm{~B})$ nanosheets orthogonally nucleate and grow along the flakes of EOG foam into a 3D nanostructured electrode.

EOG network was deposited around struts of nickel foam using PECVD process. The morphology evolution of multilayer-graphene/thin-graphite coating on nickel surface is shown in scanning electron microscope (SEM) images in Figure S1 of Supporting Information. During the 
first 2-3 minutes after plasma deposition was initiated (Figure S1a), laterally oriented film, with multiple but electrically well interconnected domains, is formed conformably along nickel surface, and nucleation of perpendicularly oriented graphite starts. As deposition process goes on, more nucleation of perpendicularly oriented graphite occurs and growth of perpendicularly oriented graphene sheets proceeds (Figure S1b, c). Finally, well-connected EOG network is formed (Figure S1d). SEM images in Figure S2a, b show the top view and the cross sectional view of as-grown EOG/Ni foam. Following EOG deposition, $\mathrm{Ni}$ was etched away in $10 \% \mathrm{HCl}$ at $80{ }^{\circ} \mathrm{C}$ to produce freestanding EOG foam.

As shown in electron microscope images in Figure 2, freestanding EOG foam has the same "macroscopic" morphology as nickel foam (Figure 2a, b), but very different "microscopic" morphology (Figure 2c, d). The cross-sectional view SEM images also show prominent contrast between EOG foam and Ni foam (Figure 2e, f). EOG foam has a hollow scaffold enclosed by the underlying continuous conformal LOG layer on which dense EOG flakes stand (Figure 2f). The inset transmission electron microscope (TEM) images and schematic in Figure 2d, f illustrate that the EOG flake, consisting of multilayer graphene (or thin graphite), has a tapered profile with a sharper tip and a wider base, and fully exposed graphene edges are located along the walls of EOG flake. Clearly, the underlying 3D continuous LOG layer can be considered to be equivalent of the previously reported LOG foam. Therefore, our EOG foam, with fully exposed active graphene edges and easily accessible large surface area to promote dense nucleation and growth of oxide materials around the framework, can provide better electrode performance over that of the previously demonstrated LOG foam. 

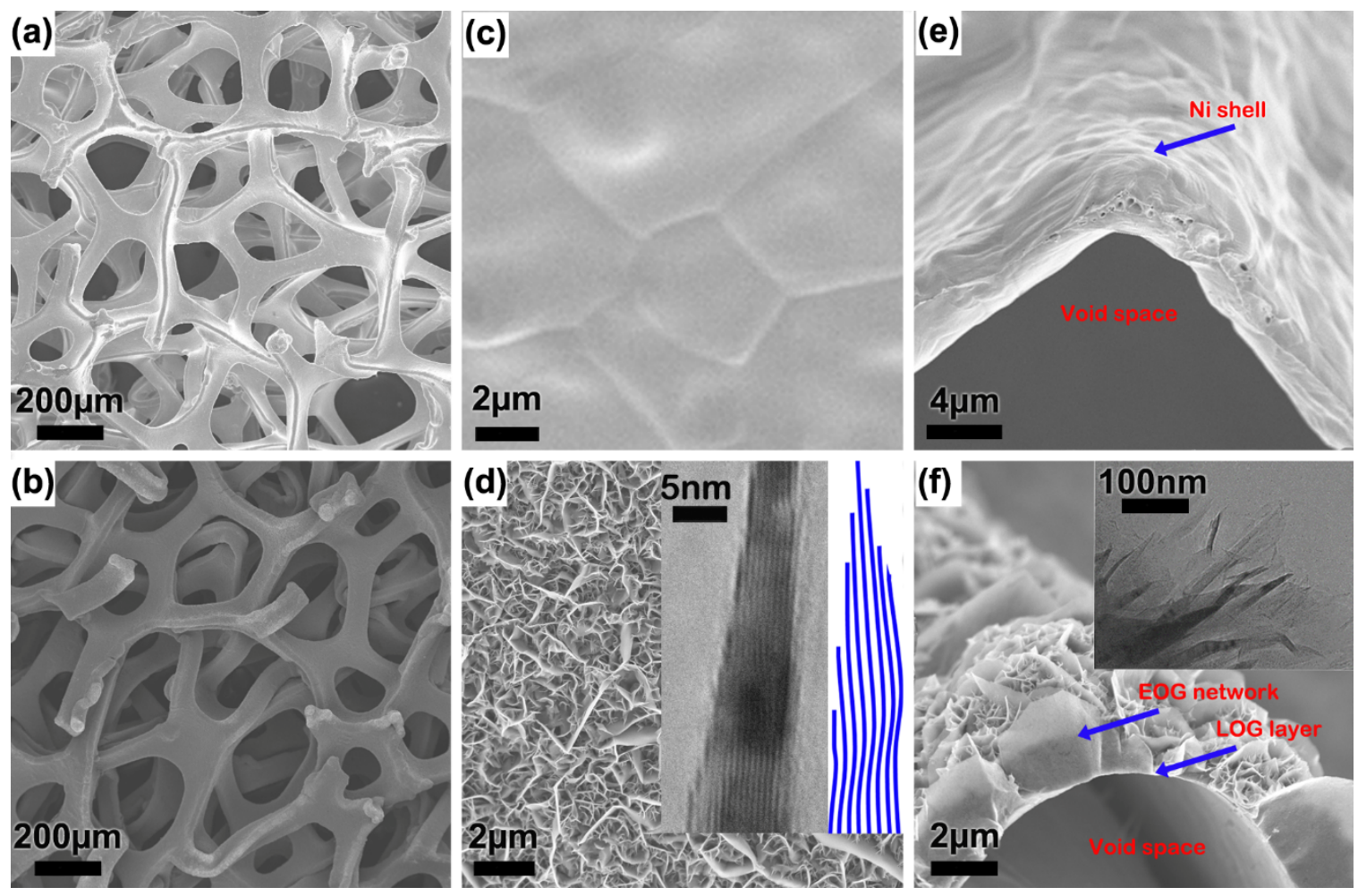

Figure 2. SEM images comparing surface morphology between Ni foam $(a, c)$ and EOG foam (b,

d) at "macro-scale" (a, b) and "micro-scale" (c, d). Cross-sectional views show that each strut of the Ni foam (e) has a thick solid wall that encloses void space, while EOG foam (f) consists of a thin LOG continuous under-layer and the EOG network located above the LOG under-layer. The inset TEM images $(d, f)$ and schematic (d) show that each EOG flake, consisting of multilayer graphenes, has a tapered profile with a sharper tip and a wider base, and fully exposed graphene edges are located along the walls of EOG flake. 


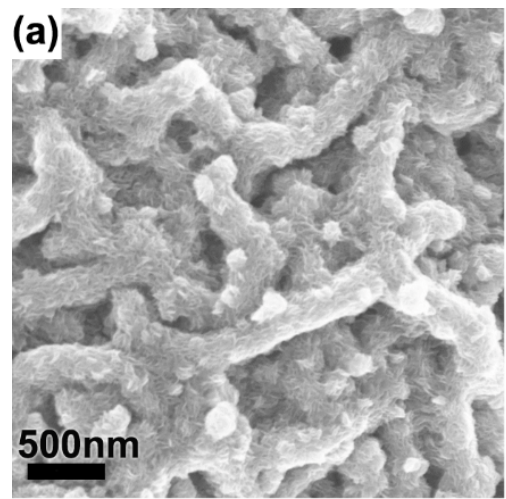

(d)

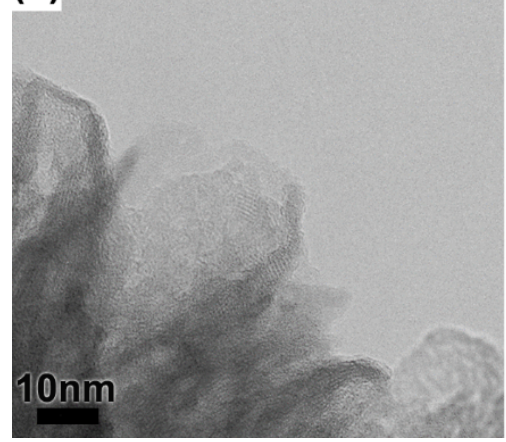

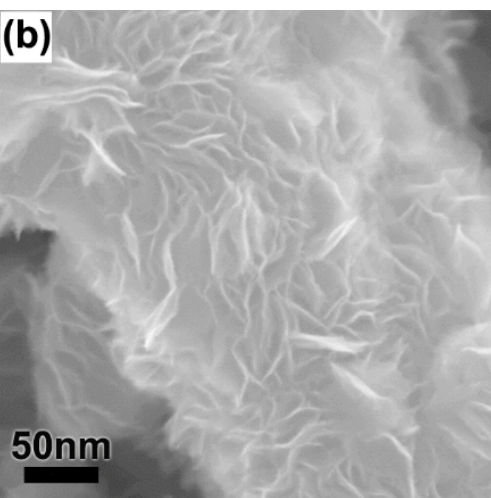

(e)

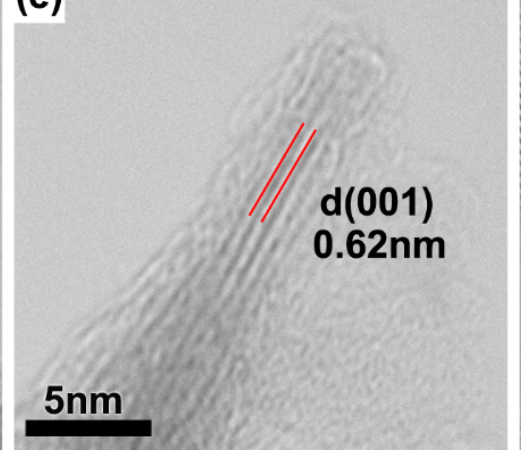

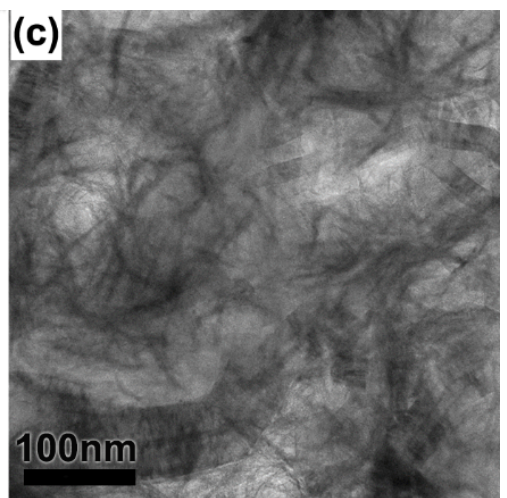

(f)

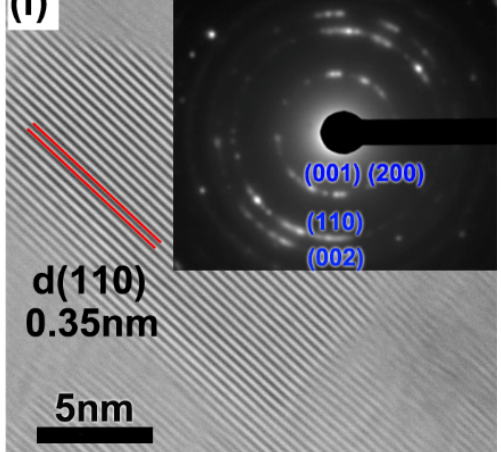

Figure 3. (a, b) SEM images of orthogonally oriented $\mathrm{TiO}_{2}(\mathrm{~B})$ nanosheets grown on EOG foam with straight pore structure between neighboring nanosheets. (c) TEM images of free $\mathrm{TiO}_{2}(B)$ nanosheets after being peeled off from EOG foam indicating a flexible sheet structure. (d) TEM image of orthogonally oriented $\mathrm{TiO}_{2}(\mathrm{~B})$ nanosheet cluster. (e) High-resolution TEM images of individual $\mathrm{TiO}_{2}(\mathrm{~B})$ nanosheets. The lattice spacing of $0.62 \mathrm{~nm}$ corresponds to the (001) crystal plane of $\mathrm{TiO}_{2}(\mathrm{~B})$. The lattice spacing of $0.35 \mathrm{~nm}$ in (f) corresponds to the (110) $\mathrm{TiO}_{2}(\mathrm{~B})$ or the (101) $\mathrm{TiO}_{2}(\mathrm{~A})$. The inset of $(f)$ is the $\mathrm{SEAD}$ pattern of $\mathrm{TiO}_{2}(\mathrm{~B})$ nanosheets, which shows lattice planes corresponding to the $\mathrm{TiO}_{2}(\mathrm{~B})$ monoclinic crystal structure.

With EOG foam serving as a substrate for heterogeneous nucleation, $\mathrm{TiCl}_{3}$ was solvothermally treated with DI water and ethylene glycol solvents. The hydrolysis of titanium precursor in the presence of ethylene glycol generated monoethylene glycol octahedra and further condensed into $\mathrm{TiO}_{2}(\mathrm{~B})$-based hydroxide. The surrounding hydrocarbon bonds may prevent the 
crosslink of Ti-O-Ti matrix, resulting in thin sheet structure.[42] After calcination to remove the water inclusions, the synthesized $\mathrm{TiO}_{2}(\mathrm{~B})$ on $\mathrm{EOG}$ foam has a morphology and structure shown in Figure 3 with a very unique hierarchical structure. Numerous $\mathrm{TiO}_{2}(\mathrm{~B})$ interwoven nanosheets grow orthogonally around each underlying graphene flake with a reasonably high packing density but with their $2 \mathrm{D}$ sheet surface easily accessible through the ordered pore orientation between neighboring sheets owing to their orthogonal growth (Figure 3a, b). Without EOG foam present in the solvothermal synthesis process to act as a heterogeneous nucleation substrate, we found $\mathrm{TiO}_{2}(\mathrm{~B})$ nanosheets self-assembled into mesoporous spheres (Figure S3), similar as reported by others.[43] The fully-exposed and highly dense graphene edges provided by EOG foam, with their unsaturated chemical bonds, act as nucleation sites to reduce the overall energy when titanium precursor concentration reaches a saturation threshold. Following the heterogeneous nucleation step, dense $\mathrm{TiO}_{2}(\mathrm{~B})$ nanosheets grow orthogonally into an ordered structure through the condensation of its precursors. Homogeneous nucleation in the solution is prevented since it generally has a higher saturation threshold than heterogeneous nucleation. The microstructure of as-made $\mathrm{TiO}_{2}(\mathrm{~B})$ nanosheets was further investigated by TEM. Figure $3 \mathrm{c}$ shows the corrugated morphology of nanosheets after being peeled off from EOG, suggesting nanosheets are very thin and flexible. Sheet-like morphology is confirmed. Figure $3 \mathrm{~d}$ further discloses the orthogonal orientation of $\mathrm{TiO}_{2}(\mathrm{~B})$ nanosheet clusters. Figure $3 \mathrm{e}, \mathrm{f}$ are the high resolution $\mathrm{TEM}$ images of $\mathrm{TiO}_{2}(\mathrm{~B})$ nanosheets indicating the crystal lattice and morphology. The sheet thickness is only 5-10 nm. These sheets have a polycrystalline structure (Figure $3 \mathrm{f}$ ). The measured lattice spacing of $0.62 \mathrm{~nm}$ exclusively corresponds to the (001) crystal plane of $\mathrm{TiO}_{2}(\mathrm{~B})$, while the $0.35 \mathrm{~nm}$ lattice spacing can be assigned either to the (110) crystal plane of $\mathrm{TiO}_{2}(\mathrm{~B})$ or the (101) crystal plane of anatase $\mathrm{TiO}_{2}(\mathrm{~A})$. The selected area electron diffraction (SAED) pattern in the inset of Figure $3 f$ further 
discloses the polycrystalline nature of the as-made $\mathrm{TiO}_{2}$. The three labeled rings from the inner to the outer side of the SAED pattern correspond to the (100), (110), and (002) crystal planes in $\mathrm{TiO}_{2}(\mathrm{~B})$ monoclinic crystal structure, respectively. A detail TEM image of the $\mathrm{TiO}_{2}(\mathrm{~B})$ sheet in Figure S4 shows the high density of nanocrystallites with different orientation and also different phases, giving a high-density of grain boundary. To further identify the crystal structure, the Xray powder diffraction (XRD) pattern and the Raman spectrum of the sample were acquired, as shown in Figure S5. In Figure S5a, the dominant XRD peaks can be assigned to $\mathrm{TiO}_{2}(\mathrm{~B})$, although several minor peaks could originate from the bronze phase or the anatase phase. Similarly, the Raman spectrum in Figure S5b suggests the inclusion of minor anatase phase in the synthesized $\mathrm{TiO}_{2}$ (B) nanosheets. This is in agreement with previous reports, which show that when using $\mathrm{TiCl}_{3}$ or $\mathrm{TiCl}_{4}$ as a precursor, the anatase phase, which is more stable than the bronze polymorph, often appears as inclusions in the synthesized $\mathrm{TiO}_{2}(\mathrm{~B})$ nanomaterials.[35, 44-46]

These orthogonally oriented nanosheets are well connected through the underlying EOG foam for rapid electron transport, and at the same time, the oriented gaps between nanosheets provide straight channels for lithium ion diffusion and margin space to alleviate the strain from volume expansion caused by lithiation. The ultrathin sheets further reduce the diffusion length for lithium ions, promising a high rate of lithium ion insertion and extraction. Combined with the intrinsic superior properties of $\mathrm{TiO}_{2}(\mathrm{~B})$ itself as electrode material, such a hierarchical structure of orthogonally oriented $\mathrm{TiO}_{2}(\mathrm{~B})$ nanosheets supported by EOG foam is a promising candidate to serve as a freestanding electrode for high-rate and highly-stable LIB technology.

Electrochemical properties and performance of LIBs based on such $\mathrm{TiO}_{2}(\mathrm{~B}) / \mathrm{EOG}$ freestanding electrodes were studied using $\mathrm{Li}$ metal as a counter electrode. $\mathrm{The}^{\mathrm{TiO}} 2$ active mass in the electrode is in the range around $0.5-1.7 \mathrm{mg} \mathrm{cm}^{-2}$. The cyclic voltammetry $(\mathrm{C}-\mathrm{V})$ curves at 
different scan rates for one representative electrode are presented in Figure 4a. These curves display three pairs of anodic and cathodic peaks, designated as $\mathrm{S}_{1}, \mathrm{~S}_{2}$, and A, respectively, similar to other reports.[25, 34] At a scan rate of $0.1 \mathrm{mV} / \mathrm{s}$, the pairs of $\mathrm{S}_{1}$ peaks are at ca. 1.5 and $1.6 \mathrm{~V}$, $\mathrm{S}_{2}$ peaks at ca. 1.6 and $1.7 \mathrm{~V}$, and A peaks at ca. 1.7 and $2.0 \mathrm{~V}$. All the peak positions slightly shift with the scan rate increase due to polarization. The two pairs of S peaks become stronger relative to the pair of A peaks as the scan rate increases. The inset of this figure shows the plots of the $\mathrm{S}_{1}$ peak current $\left(I_{S}\right)$ vs. the scan rate $(v)$ and the A peak current $\left(I_{A}\right)$ vs. the square root of the scan rate $(\sqrt{v})$. S peak currents are linear with scan rate $\left(I_{S} \propto v\right)$, behavior of pseudocapacitive charge storage mechanism, but A peak currents are linear with the square root of scan rate $\left(I_{A} \propto \sqrt{v}\right)$, representing normal diffusion controlled Faradaic processes. The two S peak pairs correspond to lithiation/delithiation of $\mathrm{TiO}_{2}(\mathrm{~B})$, while the A peaks are assigned to that of anatase impurity phase inclusion.[25] The peaks from anatase diminish with the scan rate increase. This is consistent with the charge-discharge (C-D) curves at high current densities (Figure 4b and Figure S6), revealing that $\mathrm{TiO}_{2}(\mathrm{~B})$ phase contributes the main part of the total capacity, especially at high scan rates. 

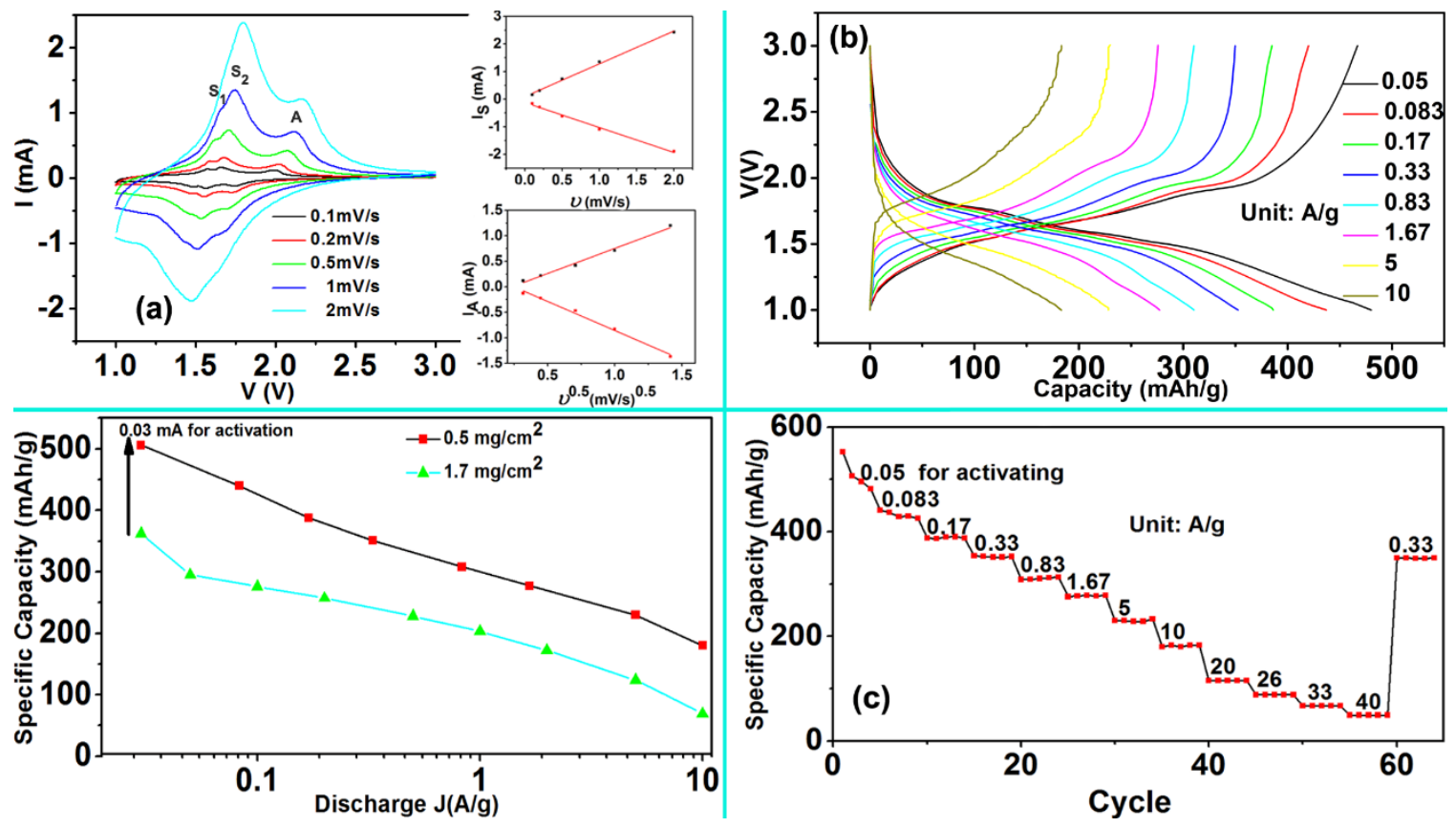

Figure 4. (a) $C$-V curves at different scan rates showing $S_{1}, S_{2}$, and A peaks. The insets are the plots of the $S_{1-}$ peak current $v$ s. the scan rate and the A-peak current vs. the square root of the scan rate. (b) C-D curves at different current density and (c) specific capacity vs. C-D cycles at different current densities for electrodes with $0.5 \mathrm{mg} \mathrm{cm}^{-2}$ active mass. (d) Capacities dependence on discharging current for electrodes with two different active mass.

The variation of gravimetric capacity with different C-D rates is presented in Figure 4b, c for electrodes with active mass of $0.5 \mathrm{mg} \mathrm{cm}^{-2}$, while the variation of capacity on discharging current for electrodes with two different mass loading is presented in Figure 4d. The C-D curves in Figure $4 \mathrm{~b}$ have the feature of gradual slopes, characterized by the non-diffusion-limited lithiation/delithiation processes in $\mathrm{TiO}_{2}(\mathrm{~B})$, i.e. the pseudocapacitive charge storage mechanism. However, at low rates, small plateaus at ca. $1.7 \mathrm{~V}$ on the charge curves (delithiation) are observable. This is caused by the diffusion-limited delithiation process in anatase $\mathrm{TiO}_{2}$, and verifies the inclusion of minor anatase phase impurity in the synthesized $\mathrm{TiO}_{2}(\mathrm{~B})$ nanosheets. The delithiation 
plateau of anatase gradually vanishes with the current density increase. This indicates that $\mathrm{Li}^{+}$ diffuses faster in $\mathrm{TiO}_{2}(\mathrm{~B})$ than in anatase and $\mathrm{TiO}_{2}(\mathrm{~B})$ contributes the major part of the total capacity, especially at high rates. A differential capacity curve derived from the C-D curve at 1.67 $\mathrm{A} \mathrm{g}^{-1}$ is plotted in Figure S6, with three peaks consistent to those in Figure 4a. From C-D data in Figure $4 \mathrm{~b}$, it is observed that at a low current of $0.05 \mathrm{~A} \mathrm{~g}^{-1}\left(\sim 0.15 \mathrm{C}\right.$ with $\left.1 \mathrm{C}=335 \mathrm{~mA} \mathrm{~g}^{-1}\right)$, the nanostructured $\mathrm{TiO}_{2}$ (B) electrode with a low mass loading exhibited an extremely large capacity of $475 \mathrm{mAh} \mathrm{g}^{-1}$ when measured between $1-3 \mathrm{~V}\left(\mathrm{vs} . \mathrm{Li}^{-} \mathrm{Li}^{+}\right)$. Interfacial charge storage, arising from the polycrystalline nanosheet structure with large surface area and nanocrystallite boundaries (Figure S4) that provide abundant sites for Li storage, contribute a significant part. These interfacial storage mechanism was first come up with by Maier[47], and further demonstrated by others' work on nanoscale $\mathrm{TiO}_{2}$ and other oxides. [48] [49, 50] In these previous studies, interfacial charge storage boosted the lithium ion storage capacity of anatase $\mathrm{TiO}_{2}$ and mixture of anatase $\mathrm{TiO}_{2}$ and $\mathrm{TiO}_{2}(\mathrm{~B})$ beyond their theoretical capacity. In the first few cycles (Figure 4b), the electrode exhibited irreversible capacity loss, caused by the irreversible interfacial reaction between $\mathrm{TiO}_{2}$ and the electrolyte. After that, the capacity is stabilized. As shown in Figure 4c, although discharge capacity gradually diminishes with current, a capacity of 352 and $49 \mathrm{mAh} \mathrm{g}^{-1}$ was measured for a current density of 0.33 and $40.0 \mathrm{~A} \mathrm{~g}^{-1}$, respectively, corresponding to a C-rate of 1 and $120 \mathrm{C}$, respectively. The capacity could restore back to $350 \mathrm{mAh} \mathrm{g}^{-1}$ when the current returned back to $0.33 \mathrm{~A} \mathrm{~g}^{-1}$, maintaining almost $100 \%$ of the initial capacity after these largecurrent cycling tests. Electrodes with higher mass loading of $1.7 \mathrm{mg} \mathrm{cm}^{-2}$ were also tested and their capacity at different current densities are plotted in Figure 4d. Although the measured capacity decreases with the active mass, a reasonable large capacity is still achieved. The relatively 
large decrease in capacity with the mass loading is caused by the EOG structure (Figure $2 b$ ). We will further discuss it later.
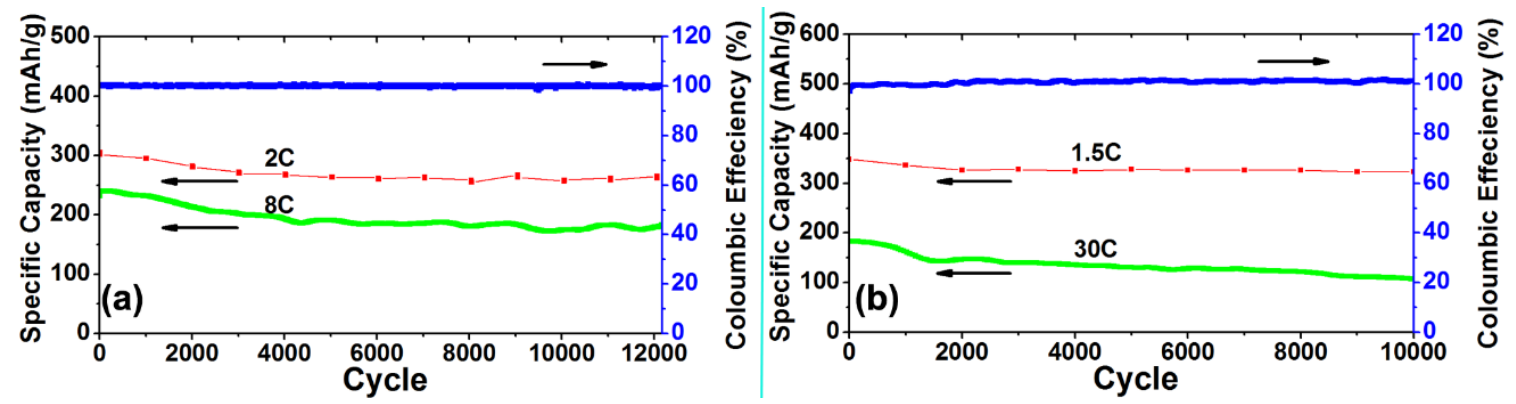

Figure 5. The $\mathrm{TiO}_{2}(\mathrm{~B}) / \mathrm{EOG}$ electrode cycling stability tests showing specific capacity and Coulombic efficiency variation with C-D cycles: (a) Continuous cycling at $2.67 \mathrm{~A} \mathrm{~g}^{-1}(8 \mathrm{C})$ and sampling at $0.66 \mathrm{~A} \mathrm{~g}^{-1}(2 \mathrm{C})$ after every 1,000 cycles, and (b) Continuous cycling at $10 \mathrm{Ag}^{-1}$ (30 C) and sampling at $0.5 \mathrm{~A} \mathrm{~g}^{-1}(1.5 \mathrm{C})$ after every 1,000 cycles.

In addition to the intrinsic high-rate property of $\mathrm{TiO}_{2}(\mathrm{~B})$ itself due to its pseudocapacitive charging/discharging mechanism, our unique hierarchical electrode structure with orthogonally oriented $\mathrm{TiO}_{2}$ (B) nanosheets grown on highly conductive EOG foam also contributes to the measured extraordinary rate performance, as confirmed by the electrochemical impedance spectroscopy (EIS) measurement, shown in Figure S7. The EIS of the LIB can be modeled based on the equivalent circuit in Figure $\mathrm{S} 7$, and a small charge-transfer resistance $\left(\mathrm{R}_{2}\right)$ of $\sim 50 \mathrm{ohm}$ was obtained. The sharp slope of the line at low frequency further indicates the fast diffusion of lithium ions in the solid state $\mathrm{TiO}_{2}(\mathrm{~B})$ nanosheets.[29, 35]

A significant performance of our $\mathrm{TiO}_{2}(\mathrm{~B}) / \mathrm{EOG}$ hierarchical electrode is its lifetime, as measured by continuous C-D cycling test shown in Figure 5. In the test of a first cell, cycling was conducted at a high current density of $2.67 \mathrm{~A} \mathrm{~g}^{-1}(8 \mathrm{C})$, with the current returned to a lower current 
density of $0.66 \mathrm{~A} \mathrm{~g}^{-1}$ (2 C) every 1,000 cycles for sampling purposes. After 12,000 cycles tested at $8 \mathrm{C}$ rate, our electrode demonstrated a capacity retention of $82 \%$ of its initial capacity; when current returned to $0.66 \mathrm{~A} \mathrm{~g}^{-1}$, the capacity maintained $86 \%$ of its initial value. We also conducted a second test for 10,000 cycles at a current density of $10 \mathrm{~A} \mathrm{~g}^{-1}(30 \mathrm{C})$. This cell maintained $60 \%$ of its initial capacity at $30 \mathrm{C}$, and surprisingly, when the current was returned to a smaller value of $0.5 \mathrm{~A} \mathrm{~g}^{-1}(1.5 \mathrm{C})$, the capacity recovered to $93 \%$ of its initial value at this current. Such an excellent cyclic stability is much better than that of LIBs based on the nanosheet-constructed $\mathrm{TiO}_{2}(\mathrm{~B})$ spheres,[34] $\mathrm{TiO}_{2}(\mathrm{~B})$ nanorod/graphene,[29] $\mathrm{TiO}_{2}(\mathrm{~B}) /$ graphene composites,[35] and $\mathrm{TiO}_{2}(\mathrm{~B})-$ based nanotubular structure.[32] To put it in a context, if an electric vehicle is fully charged and discharged once every day, 12,000 cycles will take almost 33 years and its capacity will only degrade by $18 \%$ at the very high $8 \mathrm{C}$ rate. The outstanding cycling stability of our hierarchical $\mathrm{TiO}_{2}(\mathrm{~B}) / \mathrm{EOG}$ nanostructured electrode might be attributed to several factors that include the margin space between $\mathrm{TiO}_{2}(\mathrm{~B})$ nanosheets buffering nanosheet volume expansion, the geometry of polycrystalline nanosheet itself alleviating strains as well as the intrinsic structure stability of $\mathrm{TiO}_{2}$ (B) lattice in lithiation/delithiation, a strong bonding between $\mathrm{TiO}_{2}(\mathrm{~B})$ and $\mathrm{EOG}$ scaffold that maintains the structure integrity, in addition to the chemical stability of EOG foam acting as a robust and conductive scaffold. The synergetic effects of these properties prevents active mass from pulverization and ensure the electrode integrity. Thus a long cycling stability under high rates can be achieved. Representative SEM images of $\mathrm{TiO}_{2}(\mathrm{~B})$ structure after 2,000 C-D cycles and 12,000 cycles C-D from different batteries are shown in Figure S8. After 2,000 cycles, the morphology and microstructure of $\mathrm{TiO}_{2}(\mathrm{~B})$ nanosheets do not show obvious change or damage, consistent with the high capacity retention at 2,000 cycles. Even after 12,000 cycles, only a small fraction of nanosheets was found falling off from electrodes, resulting in the measured small 
capacity loss; however, a dramatic morphology change was not observed, further confirming the electrode stability.

In Table I, we compare the performance of our $\mathrm{TiO}_{2}(\mathrm{~B}) / \mathrm{EOG}$ electrode with several representative $\mathrm{TiO}_{2}$ nanostructure electrodes reported in the literature recently, in terms of capacity, rate performance, and cycling lifetime, confirming the merits of the $\mathrm{TiO}_{2}(\mathrm{~B}) / \mathrm{EOG}$ electrode. Furthermore, it deserves to be emphasized that our electrode is freestanding that provides other benefits. The used EOG foam has a mass density of $\sim 1-1.5 \mathrm{mg} \mathrm{cm}^{-2}$, much lower than the commonly used current collector metal foils, e.g., $5.5 \mathrm{mg} \mathrm{cm}^{-2}$ for $15 \mu \mathrm{m}$ thick aluminum, and 8 $\mathrm{mg} \mathrm{cm}{ }^{-2}$ for $9 \mu \mathrm{m}$ thick copper. Furthermore, in classical powder based electrode, $20-30 \%$ of polymer binders and conductive fillers have to be added into the powder paste, while the freestanding electrode has no such inactive mass. We further point out that although the EOG foam, like the Ni foam template, has large voids, when used as electrode after compressing (Figure S9a,b), its volume is significantly reduced with a total electrode thickness of $\sim 55 \mu \mathrm{m}$, comparable with powder based electrodes. Further improvement is still necessary to increase the mass loading for practical applications, but the data presented here indicates that EOG foam is a better framework for developing freestanding electrodes, while $\mathrm{TiO}_{2}(\mathrm{~B})$, when probably grafted on a framework, is promising for developing high-rate, reliable and long lifetime batteries. 
Table 1. Performance comparison of our $\mathrm{TiO}_{2}(\mathrm{~B}) / \mathrm{EOG}$ freestanding electrode with other $\mathrm{TiO}_{2}$ electrodes from references.

\begin{tabular}{|c|c|c|c|c|c|}
\hline Electrode & Free-standing & $\begin{array}{l}\text { Active Mass } \\
\left(\mathrm{mg} / \mathrm{cm}^{2}\right)\end{array}$ & $\begin{array}{c}\text { Capacity } \\
\text { @ } 0.33 \mathrm{~A} / \mathrm{g} \\
(\mathrm{mAh} / \mathrm{g})\end{array}$ & $\begin{array}{l}\text { Capacity } \\
@ 3.4 \mathrm{~A} / \mathrm{g} \\
(\mathrm{mAh} / \mathrm{g})\end{array}$ & $\begin{array}{l}\text { Cycling } \\
\text { Stability }\end{array}$ \\
\hline $\begin{array}{l}\text { Nanoporous } \\
\mathrm{TiO}_{2}(\mathrm{~A})[48]\end{array}$ & $\mathrm{N}$ & N/A & 190 & 120 & $\begin{array}{l}100 \text { cycles } \\
@ 1.7 \mathrm{~A} / \mathrm{g} \\
20 \% \text { loss }\end{array}$ \\
\hline $\begin{array}{l}\text { Mesoporous } \mathrm{TiO}_{2}(\mathrm{~B}) \\
\text { microspheres[24] }\end{array}$ & $\mathrm{N}$ & $1-2$ & 220 & $\begin{array}{c}150 \\
\text { (a) } 5 \mathrm{~A} / \mathrm{g}\end{array}$ & $\begin{array}{l}5,000 \text { cycles } \\
\text { @ } 3.4 \mathrm{~A} / \mathrm{g} \\
10 \% \text { loss }\end{array}$ \\
\hline $\begin{array}{c}\mathrm{TiO}_{2}(\mathrm{~B}) \\
\text { nanosheet[34] }\end{array}$ & $\mathrm{N}$ & 1 & 225 & 196 & $\begin{array}{l}200 \text { cycles } \\
@ 3.4 \mathrm{~A} / \mathrm{g} \\
7 \% \text { loss }\end{array}$ \\
\hline $\begin{array}{l}\mathrm{TiO}_{2}(\mathrm{~B}) / \text { carbon } \\
\text { fabric[51] }\end{array}$ & $\mathrm{Y}$ & $1-1.2$ & 250 & 160 & $\begin{array}{l}2000 \text { cycles } \\
@ 6.7 \mathrm{~A} / \mathrm{g} \\
13 \% \text { loss }\end{array}$ \\
\hline $\begin{array}{c}\text { Elongated } \mathrm{TiO}_{2}(\mathrm{~B}) \\
\text { nanotubes[32] }\end{array}$ & $\mathrm{N}$ & $\mathrm{N} / \mathrm{A}$ & 224 & 176 & $\begin{array}{l}10,000 \text { cycles } \\
@ 8.4 \mathrm{~A} / \mathrm{g} \\
\sim 32 \% \text { loss }\end{array}$ \\
\hline $\begin{array}{l}\mathrm{TiO}_{2}(\mathrm{~B}) \text { nanosheet } \\
\text { flowers[43] }\end{array}$ & $\mathrm{N}$ & 5 & 292 & 187 & $\begin{array}{l}100 \text { cycles } \\
@ 3.4 \mathrm{~A} / \mathrm{g} \\
7.6 \% \text { loss }\end{array}$ \\
\hline $\begin{array}{c}\mathrm{TiO}_{2}(\mathrm{~B}) \\
\text { nanosheets/carbon } \\
\text { nanotube[36] }\end{array}$ & $\mathrm{N}$ & 3 & N/A & $\begin{array}{c}150 \\
\text { @ } 6 \mathrm{~A} / \mathrm{g}\end{array}$ & $\begin{array}{l}100 \text { cycles } \\
@ 0.5 \mathrm{~A} / \mathrm{g} \\
7.9 \% \text { loss }\end{array}$ \\
\hline $\mathrm{TiO}_{2}(\mathrm{~B}) /$ graphene[35] & $\mathrm{N}$ & $1-2$ & 275 & 220 & $\begin{array}{l}1,000 \text { cycles } \\
@ 13.4 \mathrm{~A} / \mathrm{g} \\
20 \% \text { loss }\end{array}$ \\
\hline $\begin{array}{c}\mathrm{TiO}_{2}(\mathrm{~B}) / \text { graphene } \\
\text { nanoscrolls[52] }\end{array}$ & $\mathrm{N}$ & N/A & 176 & 135 & $\begin{array}{l}300 \text { cycles } \\
@ 3.4 \mathrm{~A} / \mathrm{g} \\
6 \% \text { loss }\end{array}$ \\
\hline $\begin{array}{l}\mathrm{TiO}_{2}(\mathrm{~B}) \text { nanotube } \\
\text { spheres }[53]\end{array}$ & $\mathrm{N}$ & $\mathrm{N} / \mathrm{A}$ & 270 & 221 & $\begin{array}{l}1,000 \text { cycles } \\
@ 3.4 \mathrm{~A} / \mathrm{g} \\
30 \% \text { loss }\end{array}$ \\
\hline $\begin{array}{c}\mathrm{TiO}_{2}(\mathrm{~A}) \text { nanosheets } \\
/ \mathrm{TiO}_{2}(\mathrm{~B}) \text { domain[49] }\end{array}$ & $\mathrm{N}$ & 4- 6 & 250 & 150 & $\begin{array}{l}1,000 \text { cycles } \\
\text { (a) } 8.5 \mathrm{~A} / \mathrm{g}\end{array}$ \\
\hline $\mathrm{TiO}_{2}(\mathrm{R}) /$ graphene[54] & $\mathrm{N}$ & 0.5 & 200 & 153 & $\begin{array}{l}1,000 \text { cycles } \\
@ 3.4 \mathrm{~A} / \mathrm{g} \\
2 \% \text { loss }\end{array}$ \\
\hline $\begin{array}{c}\text { Mesoporous } \\
\mathrm{TiO}_{2}(\mathrm{~A}) / \text { graphene[55] }\end{array}$ & $\mathrm{N}$ & N/A & 210 & $\begin{array}{c}175 \\
\text { (a) } 1 \mathrm{~A} / \mathrm{g}\end{array}$ & $\begin{array}{l}100 \text { cycles } \\
@ 20 \mathrm{~mA} / \mathrm{g} \\
5 \% \operatorname{loss}\end{array}$ \\
\hline $\begin{array}{c}\mathrm{TiO}_{2}(\mathrm{~B}) / \mathrm{Cu} \\
\text { nanowires[56] }\end{array}$ & $\mathrm{N}$ & $1-1.4$ & 216 & 160 & $\begin{array}{l}400 \text { cycles } \\
@ 1.67 \mathrm{~A} / \mathrm{g} \\
28 \% \text { loss }\end{array}$ \\
\hline $\begin{array}{l}\mathrm{TiO}_{2}(\mathrm{~B}) / \mathrm{EOG} \text { foam } \\
\text { (this work) }\end{array}$ & $\mathrm{Y}$ & $\begin{array}{l}0.5 \\
1.7\end{array}$ & $\begin{array}{l}350 \\
245\end{array}$ & $\begin{array}{c}\sim 250 \\
150\end{array}$ & $\begin{array}{l}12,000 \text { cycles } \\
@ 2.67 \mathrm{~A} / \mathrm{g} \\
18 \% \text { loss }\end{array}$ \\
\hline
\end{tabular}


In this study, we reported the freestanding EOG foam as a 3D scaffold and using it to deposit orthogonally-oriented $\mathrm{TiO}_{2}(\mathrm{~B})$ nanosheets as nanostructured electrode for highperformance LIB. There are still enough rooms to further improve this freestanding structure by further increasing the mass loading without sacrificing the specific capacity and rate performance. Since perpendicular graphene flakes in EOG foam have a height at the scale of micrometers, the large void space $(50-100 \mu \mathrm{m})$ in Ni foam template is not fully used for EOG growth. These voids put a limit on the direct interfacial area between $\mathrm{EOG}$ and $\mathrm{TiO}_{2}(\mathrm{~B})$. When $\mathrm{TiO}_{2}(\mathrm{~B})$ mass is larger, its limited conductivity prevents the full access of all active mass. If this void dimension can be reduced by one order of magnitude through nano-engineering such as those in Ref. [1], EOG foam will be compact that can afford more mass loading for a given volume. On the other hand, it may also be envisioned that carbon nanotubes or carbon nanofibers can be vacuum filtered into the $\mathrm{Ni}$ foam template to act as extra scaffold bars so that EOG foam will be denser, and thus a larger mass of active oxides can be deposited. The current study is a steppingstone towards such developments for a rationally designed freestanding electrode architecture for high-performance energy storage devices.

In summary, EOG as a 3D scaffold was demonstrated and freestanding $\mathrm{TiO}_{2}(\mathrm{~B})$ nanostructured electrodes were constructed by employing EOG as a scaffold to grow orthogonally oriented $\mathrm{TiO}_{2}$ (B) nanosheets. Such an electrode demonstrated excellent electrochemical performance with a large specific capacity, high charging rate capability, and extremely long life time for LIBs. In addition to the intrinsic property of $\mathrm{TiO}_{2}(\mathrm{~B})$ material for lithium intercalation, all characteristics of this rationally designed nanostructure, i.e., a continuous EOG foam for electron transport, edge oriented graphene sheets for $\mathrm{TiO}_{2}(\mathrm{~B})$ nanosheet dense nucleation and growth, the orthogonally oriented $\mathrm{TiO}_{2}(\mathrm{~B})$ nanosheets with straight channels for electrolyte facile 
access of the sheet surface, and the very thin sheets for the reduced $\mathrm{Li}^{+}$transport distance synergistically contribute to the measured electrode performance. This work also demonstrates that freestanding EOG foam, which is dramatically different from the widely reported LOG foam, is a promising $3 \mathrm{D}$ scaffold to construct hierarchical structure of metal oxide and an outstanding current collector to support poorly conductive oxide materials for energy storage applications.

\section{Experiments}

\section{Preparation of freestanding EOG foam}

EOG was first deposited on Ni foam template using a microwave PECVD system. Briefly, synthesis was carried out under $\mathrm{H}_{2}$ flow $(10 \mathrm{sccm})$ and $\mathrm{CH}_{4}(10 \mathrm{sccm})$ flow at a pressure of 10 Torr for 20 minutes with microwave plasma power of $1 \mathrm{~kW}$. After EOG deposition, Ni foam template was etched away by $10 \% \mathrm{HCl}$ at $80{ }^{\circ} \mathrm{C}$ for 20 hours to produce freestanding EOG foam. The mass of the freestanding EOG is approximately $1-1.5 \mathrm{mg} \mathrm{cm}^{-2}$, depending on growth duration.

\section{Synthesis of orthogonally oriented $\mathrm{TiO}_{2}(\mathrm{~B})$ nanosheets on EOG foam}

$\mathrm{TiCl}_{3}(1-2 \mathrm{ml})$ was dissolved in deionized (DI) water $(1-2 \mathrm{ml})$ and stirred for 5 minutes. Then, ethylene glycol (32- $34 \mathrm{ml})$ was added to the solution. After stirring for 10 minutes, the solution and the EOG foam were transferred into a $45 \mathrm{ml}$ Teflon-lined autoclave and kept at $150{ }^{\circ} \mathrm{C}$ for 6 hours. The product was washed using DI water and ethanol several times. Finally, the product was dried at $80{ }^{\circ} \mathrm{C}$ in vacuum for 20 hours, and then annealed at $300{ }^{\circ} \mathrm{C}$ for 4 hours. The mass of $\mathrm{TiO}_{2}(\mathrm{~B})$ was accurately determined using a microbalance by measuring the mass difference before and after EOG coated with $\mathrm{TiO}_{2}(\mathrm{~B})$ for calculating the specific capacity. The active mass of $\mathrm{TiO}_{2}(\mathrm{~B})$ on EOG foam was controlled in the range of $0.5-1.7 \mathrm{mg} \mathrm{cm}^{-2}$. 


\section{Materials characterization, LIBs assembling and electrochemical studies}

The morphology, microstructure, and crystal structure of freestanding EOG foams and $\mathrm{TiO}_{2}(\mathrm{~B}) / \mathrm{EOG}$ electrodes were characterized by SEM, TEM, SAED, XRD, and Raman spectroscopy.

LIBs based on freestanding $\mathrm{TiO}_{2}(\mathrm{~B}) / \mathrm{EOG}$ electrodes were fabricated by sandwiching a separator between a lithium metal sheet and a $\mathrm{TiO}_{2}(\mathrm{~B}) / \mathrm{EOG}$ electrode into a coin cell in a glovebox that has both oxygen and moisture concentration below $0.1 \mathrm{ppm} . \mathrm{LiPF}_{6}(1 \mathrm{M})$ in a mixture of diethyl carbonate (DEC), dimethyl carbonate (DMC) and ethylene carbonate (EC) (1:1:1 by volume) was employed as electrolyte. The newly assembled LIB was stored in the glovebox for 12 hours before testing. For electrochemical study, the LIB was first activated by a low current density of $0.03 \mathrm{~mA}$. Then, the LIB was investigated by charge-discharge (C-D), cyclic voltammetry (C-V), and electrochemical impedance spectroscopy (EIS). C-D tests were carried out at different current densities up to $40 \mathrm{~A} \mathrm{~g}^{-1}$ over a voltage window of $1-3 \mathrm{~V}$. The $\mathrm{C}-\mathrm{V}$ tests were conducted using an electrochemical work station at different scan rates from $0.1 \mathrm{mV} \mathrm{s}^{-1}$ to $20 \mathrm{mV} \mathrm{s}^{-1}$. EIS was measured over frequency range from $1 \mathrm{MHz}$ to $0.1 \mathrm{~Hz}$ with a sinusoidal signal of $10 \mathrm{mV}$ at a bias voltage of $1.5 \mathrm{~V}$. 


\section{References}

[1] H. Zhang, X. Yu, P.V. Braun, Nature Nanotechnology, 6 (2011) 277-281.

[2] S. Chabi, C. Peng, D. Hu, Y. Zhu, Advanced Materials, 26 (2014) 2440-2445.

[3] B.L. Ellis, P. Knauth, T. Djenizian, Advanced Materials, 26 (2014) 3368-3397.

[4] Y. Zhao, B. Liu, L. Pan, G. Yu, Energy \& Environmental Science, 6 (2013) 2856-2870.

[5] S. Liu, Z. Wang, C. Yu, H.B. Wu, G. Wang, Q. Dong, J. Qiu, A. Eychmüller, Advanced Materials, 25 (2013) 3462-3467.

[6] Z. Chen, W. Ren, L. Gao, B. Liu, S. Pei, H.-M. Cheng, Nature materials, 10 (2011) 424-428.

[7] M. Cai, R.A. Outlaw, S.M. Butler, J.R. Miller, Carbon, 50 (2012) 5481-5488.

[8] Y. Tang, F. Huang, H. Bi, Z. Liu, D. Wan, Journal of Power Sources, 203 (2012) 130-134.

[9] H. Ji, L. Zhang, M.T. Pettes, H. Li, S. Chen, L. Shi, R. Piner, R.S. Ruoff, Nano Letters, 12 (2012) 24462451.

[10] N. Li, Z. Chen, W. Ren, F. Li, H.-M. Cheng, Proceedings of the National Academy of Sciences, 109 (2012) 17360-17365.

[11] G. Zhou, L. Li, C. Ma, S. Wang, Y. Shi, N. Koratkar, W. Ren, F. Li, H.-M. Cheng, Nano Energy, 11 (2015) 356-365.

[12] J.R. Miller, R.A. Outlaw, B.C. Holloway, Science, 329 (2010) 1637-1639.

[13] G. Ren, X. Pan, S. Bayne, Z. Fan, Carbon, 71 (2014) 94-101.

[14] Y. Gao, Y.S. Zhou, M. Qian, X.N. He, J. Redepenning, P. Goodman, H.M. Li, L. Jiang, Y.F. Lu, Carbon, $51(2013) 52-58$.

[15] X. Xiao, P. Liu, J.S. Wang, M. Verbrugge, M.P. Balogh, Electrochemistry Communications, 13 (2011) 209-212.

[16] X. Pan, K. Zhu, G. Ren, N. Islam, J. Warzywoda, Z. Fan, Journal of Materials Chemistry A, 2 (2014) 12746-12753.

[17] G. Ren, M.N.F. Hoque, X. Pan, J. Warzywoda, Z. Fan, Journal of Materials Chemistry A, 3 (2015) 1078710794.

[18] Z. Bo, S. Mao, Z.J. Han, K. Cen, J. Chen, K.K. Ostrikov, Chemical Society Reviews, 44 (2015) 21082121. 
[19] G. Armstrong, A.R. Armstrong, P.G. Bruce, P. Reale, B. Scrosati, Advanced Materials, 18 (2006) 25972600.

[20] A.G. Dylla, G. Henkelman, K.J. Stevenson, Accounts of Chemical Research, 46 (2013) 1104-1112.

[21] A.S. Dalton, A.A. Belak, A. Van der Ven, Chemistry of Materials, 24 (2012) 1568-1574.

[22] M. Zukalova, M. Kalbac, L. Kavan, I. Exnar, M. Graetzel, Chemistry of Materials, 17 (2005) 1248-1255.

[23] Y. Ren, Z. Liu, F. Pourpoint, A.R. Armstrong, C.P. Grey, P.G. Bruce, Angewandte Chemie, 124 (2012) 2206-2209.

[24] H. Liu, Z. Bi, X.G. Sun, R.R. Unocic, M.P. Paranthaman, S. Dai, G.M. Brown, Advanced Materials, 23 (2011) 3450-3454.

[25] A.R. Armstrong, G. Armstrong, J. Canales, R. Garcia, P.G. Bruce, Advanced Materials, 17 (2005) 862865.

[26] Z. Yang, G. Du, Z. Guo, X. Yu, Z. Chen, T. Guo, H. Liu, Journal of Materials Chemistry, 21 (2011) 85918596.

[27] J. Li, W. Wan, H. Zhou, J. Li, D. Xu, Chemical Communications, 47 (2011) 3439-3441.

[28] T. Lan, J. Dou, F. Xie, P. Xiong, M. Wei, Journal of Materials Chemistry A, 3 (2015) 10038-10044.

[29] M. Zhen, S. Guo, G. Gao, Z. Zhou, L. Liu, Chemical Communications, 51 (2015) 507-510.

[30] H. Huang, J. Fang, Y. Xia, X. Tao, Y. Gan, J. Du, W. Zhu, W. Zhang, Journal of Materials Chemistry A, 1 (2013) 2495-2500.

[31] S. Brutti, V. Gentili, H. Menard, B. Scrosati, P.G. Bruce, Advanced Energy Materials, 2 (2012) 322-327.

[32] Y. Tang, Y. Zhang, J. Deng, J. Wei, H.L. Tam, B.K. Chandran, Z. Dong, Z. Chen, X. Chen, Advanced Materials, 26 (2014) 6111-6118.

[33] K. Shin, H.J. Kim, J.-M. Choi, Y.-M. Choi, M.S. Song, J.H. Park, Chemical Communications, 49 (2013) 2326-2328.

[34] S. Liu, H. Jia, L. Han, J. Wang, P. Gao, D. Xu, J. Yang, S. Che, Advanced Materials, 24 (2012) 3201-3204.

[35] V. Etacheri, J.E. Yourey, B.M. Bartlett, ACS Nano, 8 (2014) 1491-1499.

[36] C. Chen, X. Hu, Z. Wang, X. Xiong, P. Hu, Y. Liu, Y. Huang, Carbon, 69 (2014) 302-310.

[37] H.B. Wu, X.W.D. Lou, H.H. Hng, Chemistry-A European Journal, 18 (2012) 3132-3135.

[38] S. Yang, X. Feng, K. Müllen, Advanced Materials, 23 (2011) 3575-3579. 
[39] T. Beuvier, M. Richard-Plouet, M. Mancini-Le Granvalet, T. Brousse, O. Crosnier, L. Brohan, Inorganic Chemistry, 49 (2010) 8457-8464.

[40] X. Yan, Y. Zhang, K. Zhu, Y. Gao, D. Zhang, G. Chen, C. Wang, Y. Wei, Journal of Power Sources, 246 (2014) 95-102.

[41] Y. Ren, Z. Liu, F. Pourpoint, A.R. Armstrong, C.P. Grey, P.G. Bruce, Angewandte Chemie, 124 (2012) 2206-2209.

[42] G. Xiang, T. Li, J. Zhuang, X. Wang, Chemical Communications, 46 (2010) 6801-6803.

[43] H. Huang, Z. Yu, W. Zhu, Y. Gan, Y. Xia, X. Tao, W. Zhang, Journal of Physics and Chemistry of Solids, 75 (2014) 619-623.

[44] T. Beuvier, M. Richard-Plouet, L. Brohan, The Journal of Physical Chemistry C, 113 (2009) 13703-13706.

[45] A.G. Dylla, J.A. Lee, K.J. Stevenson, Langmuir, 28 (2012) 2897-2903.

[46] M.B. Yahia, F. Lemoigno, T. Beuvier, J.-S. Filhol, M. Richard-Plouet, L. Brohan, M.-L. Doublet, The Journal of Chemical Physics, 130 (2009) 204501.

[47] J. Maier, Nature Materials, 4 (2005) 805-815.

[48] J.Y. Shin, D. Samuelis, J. Maier, Advanced Functional Materials, 21 (2011) 3464-3472.

[49] Q. Wu, J. Xu, X. Yang, F. Lu, S. He, J. Yang, H.J. Fan, M. Wu, Advanced Energy Materials, 5 (2015).

[50] H. Song, N. Li, H. Cui, X. Wen, X. Wei, C. Wang, CrystEngComm, 15 (2013) 8537-8543.

[51] S. Liu, Z. Wang, C. Yu, H.B. Wu, G. Wang, Q. Dong, J. Qiu, A. Eychmüller, Advanced Materials, 25 (2013) 3462-3467.

[52] X. Li, Y. Zhang, T. Li, Q. Zhong, H. Li, J. Huang, Journal of Power Sources, 268 (2014) 372-378.

[53] Y. Cai, H.-E. Wang, S.-Z. Huang, J. Jin, C. Wang, Y. Yu, Y. Li, B.-L. Su, Scientific Reports, 5 (2015) 11557.

[54] T. Lan, H. Qiu, F. Xie, J. Yang, M. Wei, Scientific Reports, 5 (2015) 8498.

[55] W. Li, F. Wang, Y. Liu, J. Wang, J. Yang, L. Zhang, A.A. Elzatahry, D. Al-Dahyan, Y. Xia, D. Zhao, Nano Letters, 15 (2015) 2186-2193.

[56] H. Hu, L. Yu, X. Gao, Z. Lin, X.W.D. Lou, Energy \& Environmental Science, 8 (2015) 1480-1483. 